\title{
Ecosystem Function Analysis: Measuring and Monitoring for Mine Closure and Completion in Australia and Abroad — 1994 to 2008
}

\author{
H.W.B. Lacy Outback Ecology, Australia \\ T. File Outback Ecology, Australia \\ B. Biggs Valback EMS, Australia
}

\begin{abstract}
The application of ecosystem function analysis (EFA) in Australia has, at times, been considered a controversial process as it evolved from an earlier application, landscape function analysis (LFA), which was used to assess the sustainability of rangeland environments. EFA was developed by CSIRO as a monitoring tool for wider application. Its potential for application in other environments was soon realized and it has proven to be a valuable tool in the assessment and measurement of the functional processes in mine rehabilitation. In the mining industry, it involves assessment of four components namely landscape function analysis, vegetation, erosion, and habitat complexity, using simple, scientifically-validated indicators. EFA involves monitoring a range of parameters which relate to the biophysical functioning of the landscape and provides a relatively simple, cost-effective, repeatable system to scientists and managers as to how rehabilitation programmes are developing and performing over time.

EFA has the potential to play a critical role in a balanced environmental monitoring strategy in any mining or landform rehabilitation programme. EFA can fill the gap between superficial monitoring programmes, that cover large areas, primarily targeted at identifying changes or trends in the environment, such as remote sensing and aerial photography as well as intensive ground-based monitoring programmes such as fauna and flora surveys.

This paper discusses the role that EFA can play in providing information that links the development of vegetation, soils and nutrients with ecosystems and enables rapid detection of any requirement for intervention or implementation of more detailed or focused studies. Moreover it develops the role EFA can play in a balanced and integrated toolbox of monitoring techniques which are efficient, cost effective and provide the necessary data to enable managers to make informed decisions on their rehabilitation programmes. The paper also discusses the present application of EFA/LFA monitoring techniques in Australia, and other parts of the world and how these techniques are used in different regimes to complete rehabilitation and closure.
\end{abstract}

\section{Introduction}

One of the many challenges facing land managers undertaking rehabilitation or remediation works is to monitor or measure how their rehabilitation programme is performing effectively. Good management decisions require accurate information collected over time to indicate trends in performance, indicate where management intervention is required, and provide an ongoing record of activities. The complexity of the systems being managed requires an integrated monitoring strategy utilizing a range of techniques over the life of the project to provide this information - described by Tongway and Ludwig (2006), as the "toolbox".

The specific techniques being applied will vary over time as the rehabilitation or remediation progresses and the type of information required changes. The intensity of data collection will also vary over time with predisturbance baseline and early establishment stages requiring intensive detailed data capture, while broadertrend-based data capture is required to measure the developing maturity of the system.

As the rehabilitation area matures the manager needs to know that the system is tending toward a robust, sustainable state and that the components of the system are developing towards a desired end point. EFA information can indicate which aspects are developing adequately and those that are not. Areas of poor 
performance can then be targeted with focused studies to identify causes and direct what management intervention is required. This information can then be fed back into an adaptive management system as demonstrated in Figure 1 (Ward et al., 2006).

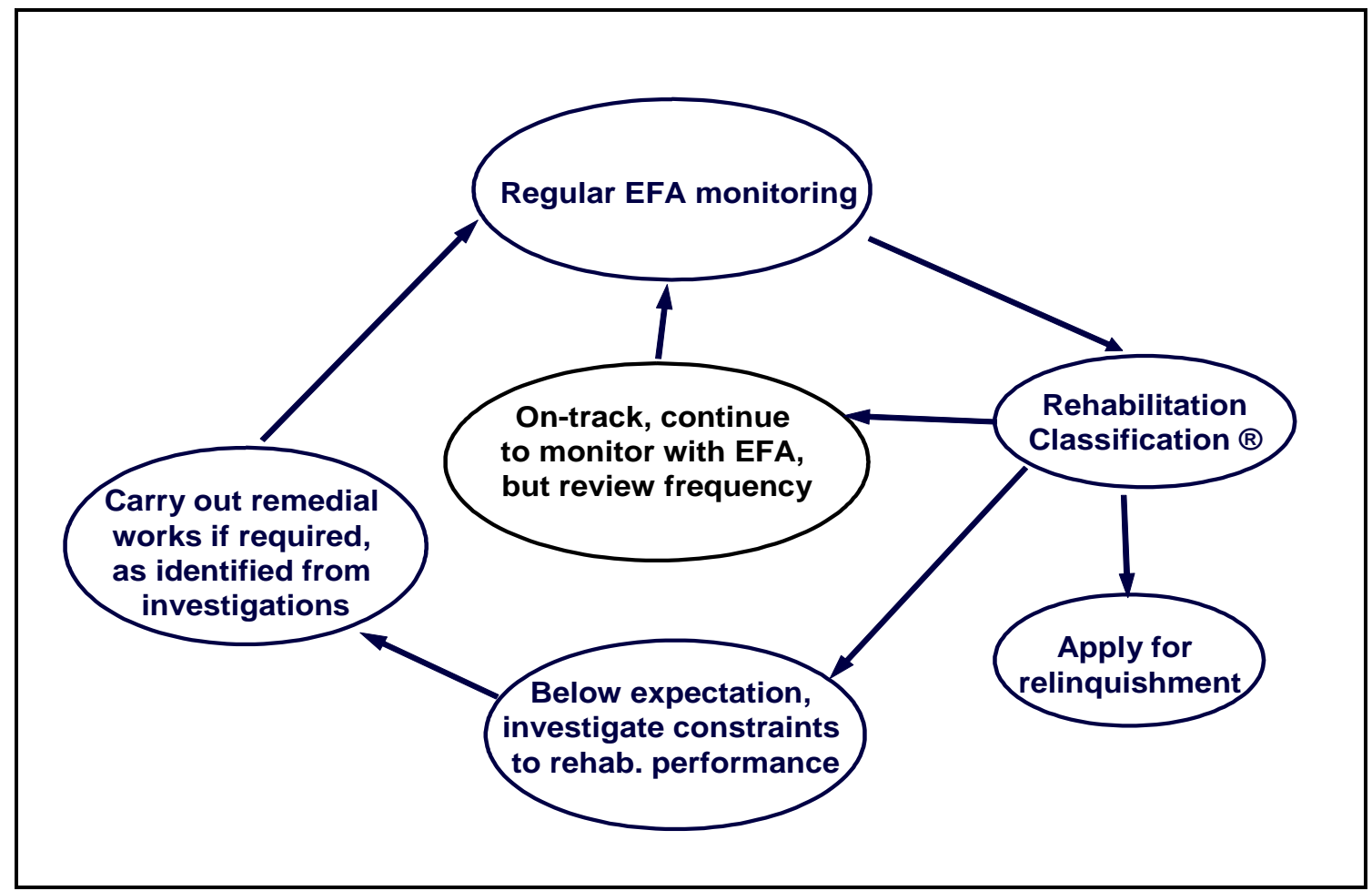

Figure 1 Rehabilitation Classification ${ }^{\circledR}$ framework (Ward et al., 2006)

A further challenge facing land managers is how to demonstrate to their stakeholders that they are achieving the outcomes they set out to achieve. This requires adequate measurement of rehabilitation performance over time to provide context to the information. Often a comparison of the performance of rehabilitation areas with other similar areas exposed to similar abiotic and biotic influences is necessary and required, commonly referred to as analogues or reference areas.

\section{$2 \quad$ Integrated monitoring systems}

An integrated monitoring system is one that collects data over time, providing the land manager with the information needed to make timely decisions on management of the rehabilitation. The complexity of the monitoring system should be tailored to the specific area in question, and the capacity of management to respond adequately. In an ideal world, monitoring and survey data collection would commence before the initial disturbance takes place. This builds an understanding of the environment being disturbed; identifying resources that the system needs to function effectively, and provide the metrics to set criteria for rehabilitation success.

An integrated monitoring system will typically include a set of tools in the toolbox that will identify and measure climate, landscape characteristics, soil properties, surface and groundwater characteristic, fauna and flora and their associations, habitat features, as well as historical management and social requirements. The authors propose the classification of these tools according to the resolution and level of detail they can measure (Table 1). 
Table 1 Components of an integrated monitoring toolbox

\begin{tabular}{|c|c|c|}
\hline Level of detail & Resolution & Tools \\
\hline $\begin{array}{l}\text { Regional catchment - } \\
\text { landscape scale }\end{array}$ & Low to medium & $\begin{array}{l}\text { Remote sensing imagery: } \\
\text { - Satellite } \\
\text { - Aerial } \\
\text { - Visual frequencies (photography) } \\
\text { - Land systems survey }\end{array}$ \\
\hline $\begin{array}{l}\text { Local catchment units } \\
\text { within distinct land } \\
\text { systems }\end{array}$ & Medium to high & $\begin{array}{l}\text { Remote-sensing imagery } \\
\text { Ecosystem function analysis including } \\
\text { landscape function analysis } \\
\text { Flora - fauna: presence and absence } \\
\text { Vegetation mapping - community level } \\
\text { Habitat mapping } \\
\text { Erosion monitoring - large scale }\end{array}$ \\
\hline $\begin{array}{l}\text { Distinct feature/unit } \\
\text { mapping rehabilitation } \\
\text { areas within specific } \\
\text { landforms }\end{array}$ & High & $\begin{array}{l}\text { Ecosystem function analysis } \\
\text { Landscape function analysis } \\
\text { Fauna and flora surveys species level } \\
\text { Vegetation mapping to within communities } \\
\text { Habitat mapping - localized } \\
\text { Soil survey } \\
\text { Groundwater/water quality surveys }\end{array}$ \\
\hline
\end{tabular}

\section{The role of LFA and EFA in land management}

LFA and EFA are tools that bring together a number of different components that, when measured over time, provide an accurate indication of how a distinct rehabilitation area is performing, and advancing toward a functioning system. An example of a toolbox that may be chosen for a specific site is provided in Figure 2 (Outback Ecology, 2005a). A comparison with data collected from reference sites with similar characteristics, but under ambient conditions, will account for seasonal and external effects beyond the control of the manager and enables a direct comparison of performance.

For a system to be developing towards sustainability, it must be accumulating resources faster than they are lost. A functional landscape is one where vital resources such as water, plant litter and topsoil are retained and efficiently used (cycled) within the boundaries of the landscape and released very slowly (Tongway and Ludwig, 2006). Typical indicators of resources that one would expect to see accumulating may include clay, silt, litter, seed, scats, and detritus. Stable soils with good structure are essential to enable continuing plant growth and development through the provision of nutrients, moisture and a sound medium to provide physical support to plants. Soils must be resistant to erosion and enable effective infiltration and retention of incident rainfall to provide ongoing resources for the plant communities they support. The movement of resources within a system has been more recently described in a paper presented at the first of the international seminars on Mine Closure (Tongway and Ludwig, 2006).

LFA provides a rapid assessment of this functionality. It measures soil stability, infiltration/run-off rates and nutrient cycling. When combined with vegetation and habitat monitoring, and some simple erosion assessments, EFA can provide an effective measure of how the biogeochemical components of an ecosystem are functioning. Applied to rehabilitated or remediated land, it can be used to assess the functionality of the system and is effective in measuring systems that are functional, through to dysfunctional.

When applied over time, results can be analyzed to identify trends in the progress of the rehabilitation or remediation. Ecosystem development typically follows a sigmoidal pattern as it develops towards maturity. 
Plotting LFA data over time can demonstrate progress along this curve and is common in biological literature (Krebs, 1985), and critical in understanding the interplay between the biological component and the geotechnical component of landscape function (Tongway and Ludwig, 2006). The EPA (2006) stated that trajectory analysis is one of three recognized strategies used to evaluate rehabilitated landscapes. The EPA went on to recognize that trajectory analysis is provided by EFA.

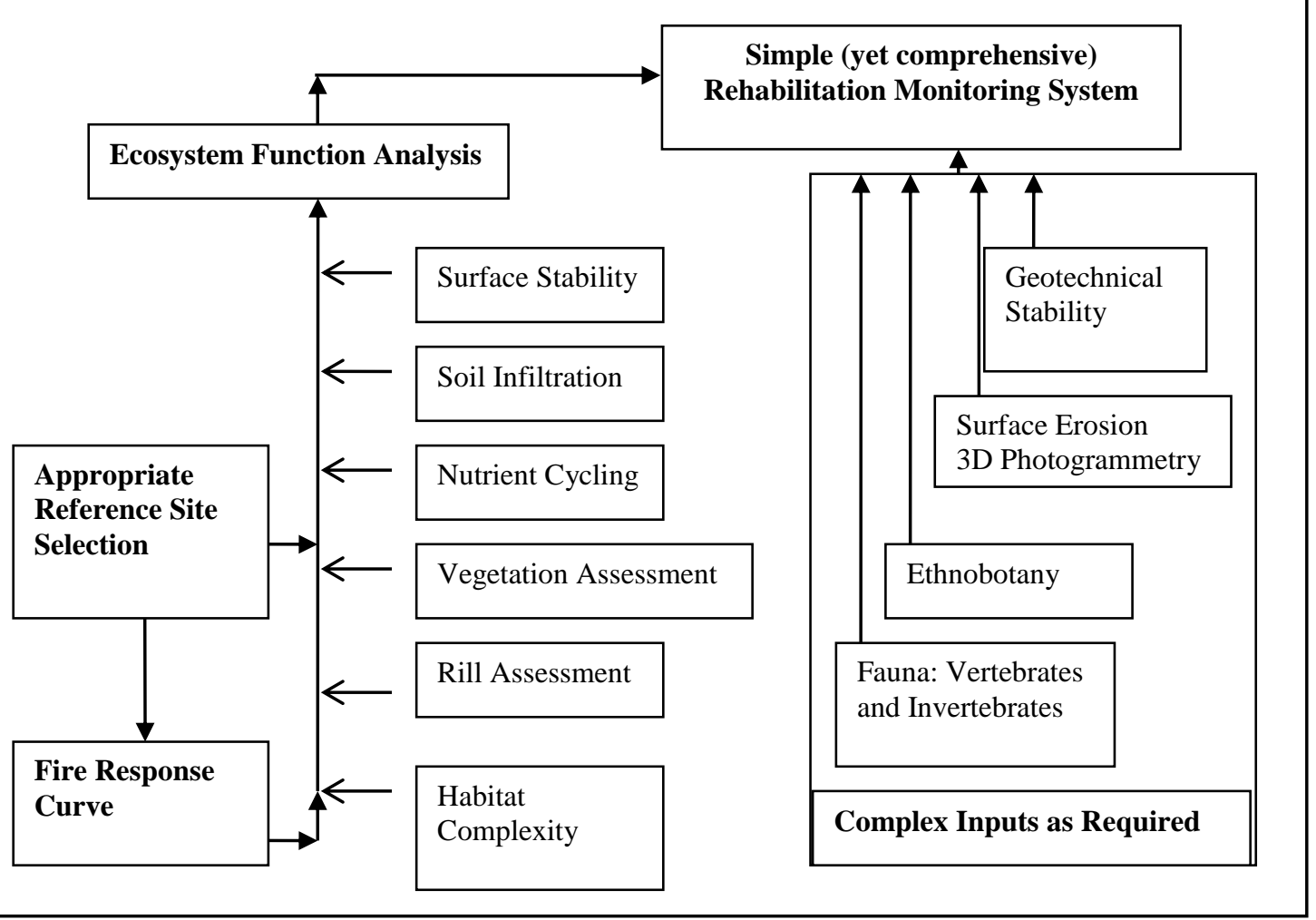

Figure 2 A toolbox example adapted from flow diagram of a rehabilitation monitoring regime and criteria development (Outback Ecology, 2005a), for a site with specific criteria

The time it takes to reach the point of inflexion on the sigmoidal curve can be used as a critical indicator in the development of rehabilitation moving toward a sustainable functional system. Where measurements from suitable reference sites are available, the inflection point can be calculated and an expected curve can be drawn at the beginning of the rehabilitation process and with these criteria identified, progress towards that point can be monitored by EFA. This can provide confidence for all parties that rehabilitation is making progress, will potentially be successful, and will ultimately lead to relinquishment of liability. As more data is presented on rehabilitation performance, and confidence increases in using position on the performance curve to signify long-term sustainability of the system, regulators and other stakeholders, in consultation with the land managers, will be able to set a point on the curve as a consistent measure of completion.

\section{The role of LFA and EFA in regulation}

In protecting the social and environmental values of the community, regulators must establish acceptable standards of rehabilitation and remediation for land managers to achieve. These are generally developed or negotiated in consultation with the land managers responsible for the land in question. Once established, the role of the regulator is to ensure these standards are met within reasonable timeframes. In the mining industry, some form of insurance or surety is usually required and is often in the form of security bonds provided by the operator and held by government. In order to make decisions on reducing or returning these bonds, the regulator must have sufficient evidence to support any claim from the land manager that the rehabilitation or remediation has achieved agreed or acceptable standards or outcomes. 
Data derived from LFA and EFA provides the regulator with this information. In the same way it provides information to the land manager on the progress of rehabilitation and these techniques also provide the regulator with a balanced picture of the developing ecosystem that can be compared directly with other similar areas. Along with other information such as plant and animal diversity, groundwater recovery and landscape design, EFA and LFA provide the regulator with sufficient information to judge confidently the performance and acceptability of the rehabilitation or remediation in question. The simplicity and repeatability of EFA and LFA mean that the regulators can easily verify for themselves the information that has been presented is correct. Regulators have been seeking consistent measures such as this for some time which will make their task, in making consistent judgments on rehabilitation success, far easier.

\section{The history of the development of LFA}

CSIRO Australia originally developed landscape function analysis (LFA) in Australia approximately 25 years ago as a monitoring tool that uses 11 indices (surface soil assessment indices), for application by Australian rangeland managers and scientists. The tool was drawn from a wide range of scientific disciplines and with applied research conducted by scientists over decades. From LFA, the broader ecosystem function Analysis (EFA) technique was developed to assess the functional status of natural and rehabilitated ecosystems. This expanded method incorporates three main modules (Figure 3), which are:

- LFA depicted as the central core.

- Vegetation structure and composition that surrounds the core.

- Habitat complexity.

EFA uses simple, scientifically-validated indicators for monitoring what relates to the biophysical functioning of the landscape. EFA differs from conventional monitoring in that the components (LFA and habitat complexity) use simple, rapid visual and sensory indicators, rather than being bound to purely quantitative presence and the absence of data of selected biota and features. EFA consists of four modules: a conceptual framework, a field methodology, a data reduction package and an interpretational framework, (Ludwig et al., 1997) which are extensively described at: www.cse.au/research/program3/efa/. EFA is applicable in most ecosystems as it focuses on a set of standard principles of ecosystem development and biogeochemical interrelationships. The method has been successfully used to assess a variety of rehabilitated ecosystems from coastal sands, eucalypt forest, tropical ecosystems and desert landscapes, and is applicable to a diversity of climatic zones, soil and waste materials, and plant communities (Ward et al., 2006).

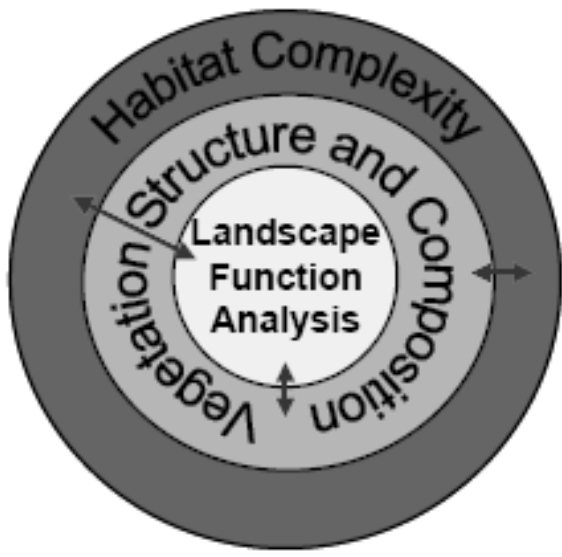

Figure 3 Schematic showing the inter-relationship of the three primary components that are integrated to form EFA (Tongway and Hindley, 2004) 


\section{EFA application in the Australian mining industry and abroad}

\subsection{Introducing EFA to the mining industry}

The mining industry recognized the potential value and versatility of EFA in the mid-1990s. Subsequently, an initial study was instigated by ACMER (then ACMRR), funded by Australian Minerals Industry Association Ltd (AMIRA) to evaluate the application of EFA within the mining sector. The project concluded in September 1997 and showed that the EFA assessment procedure could potentially be used for a wide range of mine types distributed across the continent without modification between sites (Tongway et al., 1997).

Despite progress toward project goals, it was decided that a more rigorous scientific assessment would be required to gain regulatory acceptance of the technique. Stage two of the verification was approved and undertaken between 2001 and 2003 (Tongway and Hindley, 2003). Field and laboratory investigations were executed at eight mines in Australia and one in Indonesia, encompassing bauxite, mineral sands, hard rock and coal operations. The principal objective was to verify that previously-suggested indicators of mine site rehabilitation success by the LFA monitoring procedure properly represented soil properties measured by conventional field and laboratory procedures.

The second EFA verification study found that:

- EFA indicators were shown to have a high degree of correspondence with measured soil properties.

- Mined land presents unique and difficult places to apply conventional field soil procedures.

- The EFA field technique reviewed at each site was found to be generically applicable.

- EFA has the potential to provide a spatially extensive data set over time at a fraction of the cost of biophysical measurements.

- The method was applied effectively across mines within deserts receiving annual rainfall of $200 \mathrm{~mm}$ to tropical rainforests receiving $4000 \mathrm{~mm}$ a year (Tongway and Hindley, 2003).

\subsection{The process of EFA implementation within the mining industry}

Outback Ecology was amongst consulting and mining organisations that first recognized EFA as a monitoring tool that could be readily implemented to demonstrate rehabilitation success. The EFA concept was initially taken up by a select group of mining companies in the late 1990s. These companies commissioned Outback Ecology and other consulting organisations to establish EFA monitoring programmes on rehabilitated mining landforms throughout their operations. These pioneer programmes, most of which are still active, were the flagship for EFA within Western Australia, and have directly resulted in the progressive recovery of millions of dollars in financial sureties for the mining companies. During the same time on the other side of the continent, visionary environmental managers within the Queensland Bowen Basin coal mining industry were also beginning to use EFA programmes as a quantitative rehabilitation assessment (McNamara et al., 1999).

During the establishment of these initial EFA programmes, we recognized the importance of developing a framework to show environmental managers and regulators how EFA could be applied to mining operations, on an annual basis as a tool for demonstrating progressive rehabilitation success and subsequent staged reduction in financial sureties held over rehabilitated mining landforms. The opportunity to achieve staged reductions in sureties is one of the most powerful tools available to promote innovative design, progressive rehabilitation, establishment of completion criteria and ongoing performance monitoring in the mining industry (Mackenzie et al., 2007). Subsequently, a key driver for implementing EFA within the mining industry was the opportunity to implement staged reductions in liabilities.

EFA monitoring is carried out on an annual basis, and preferentially at the same time each year. Data is then reviewed and the rehabilitation performance of each landform is assessed. Based on results, a set of recommendations can be provided which include: 
- Rehabilitation or remediation strategies required to progress the performance of unsuccessful rehabilitation.

- Investigations required to determine constraints/limitations to rehabilitation which is performing poorly.

- The level of monitoring effort (frequency and intensity) required in the forthcoming reporting period.

- An inventory of rehabilitated landforms for which partial or full recovery of financial sureties can be applied, based on demonstrated rehabilitation success.

These sets of recommendations are then used by the environmental manager to drive the progressive rehabilitation and closure programme for the mining operation.

A component of the implementation process was to introduce stakeholders to the EFA monitoring framework. This was, and still is, undertaken via a number of avenues including conferences, publications, presentations at industry events, functions and customized training workshops. Training workshops have been one of the more successful forums in providing the industry with hands-on experience and confidence in the application of EFA, and is critical for accurate use and interpretation of the outputs of the tool.

To date, training workshops have been conducted on mining operations in five Australian states including the Northern Territory, New South Wales, Queensland and Tasmania, encompassing a diverse group of mining operations, including coal, gold, copper, mineral sands and iron ore operations. Recently, workshops have been conducted within the South African Witwatersrand gold fields, platinum mines and for mines in Namibia. A maximum of 12 participants per workshop is generally maintained to enable sufficient personalized instruction from the course facilitator and trainers. Receiving direct training from the founders of EFA is seen as an important step to ensuring the methodology remains consistent throughout the industry. There are examples throughout the industry of unsuccessful EFA programmes being set up by individuals who have received "second-hand" training in EFA field procedures, concepts and data interpretation. Additionally, on-site training within mining environments enables the instructor to illustrate points gained during the workshop experience that cannot be readily written into a manual (D.J. Tongway, pers. comm., 2008).

Demonstrating to regulators that EFA could be used to determine rehabilitation performance accurately was a crucial step in implementing EFA within the mining industry. Regulatory confidence in EFA within Western Australia was gained via training workshops and a thorough examination of early EFA programmes established within the goldfields. When conducting annual regulatory assessments of rehabilitated mining landforms on which EFA programmes had been established, regulators were now becoming armed with hard data that could be taken into the field. Scrutinizing EFA monitoring results and conclusions, while standing on a rehabilitated landform, enabled regulators to verify the accuracy of information generated by EFA programmes from an on-the-ground perspective. Additionally, as more mining operations included EFA as part of their annual environmental-monitoring programmes, a greater volume of data was being generated and regulatory confidence began to grow. Regulators increasingly acknowledged EFA as an effective tool for gauging rehabilitation success and subsequently more mining companies began to implement programmes in their operations throughout the country.

\subsection{The present uptake of EFA in the Australian mining industry}

Over the past decade, EFA monitoring programmes have been established in both active and closed mining operations throughout six Australian states. Outback Ecology alone has implemented and managed EFA programmes in over 60 mining operations throughout Australia in five states, and established approximately 1760 permanent EFA transects on a wide range of features including waste rock landforms, tailings storage facilities, in-filled mining voids, tailings facilities and over-exploration disturbance. The authors are aware of at least six other consultancies using the tool in Australia. 
This successful uptake of EFA as one of the key rehabilitation monitoring tools used within the Australian mining industry can be attributed to:

- Regulator acceptance and promotion of EFA as a tool to demonstrate rehabilitation performance and provide evidence that agreed closure criteria have been achieved.

- Recognition by environmental managers that EFA is a powerful tool for monitoring the success of rehabilitation/remediation techniques and rehabilitation performance.

- The potential for EFA to be used as acceptable evidence to support progressive reduction of financial sureties held over mining areas.

- Its application in diverse mining landscapes across a range of climates and environments.

- The fact that it is simple, repeatable and inexpensive.

A contributing factor to the successful uptake of EFA has been a well-coordinated training programme. Regulators who have undergone training in the application of EFA field procedures understand and have confidence in the analysis and interpretation of EFA data (Mackenzie et al., 2007; PIRSA, 2006). Land management staff from regulatory agencies in most states have taken part in EFA training. For example, the Department of Industry and Resources (DoIR) in Western Australia has recognized EFA as an effective tool in demonstrating that rehabilitation has been successful and they used the data to validate applications for reduction in financial sureties held over rehabilitated mining landforms.

Because it focuses on standard principles of ecosystem development and biogeochemical interrelationships, EFA programmes are effectively running on mining operations which are diverse in:

- Commodity type: Programmes are currently established in gold, coal, iron ore, bauxite, mineral sands, nickel, base metals, diamond and uranium operations.

- Climate: EFA is currently carried out on a variety of mine sites, from those in desert environs receiving an annual rainfall of less than $90 \mathrm{~mm}$ (Beverly Uranium Mine in South Australia) to tropical environs receiving in excess of $1700 \mathrm{~mm}$ per annum (Woodcutters mine in Northern Territory).

- Soils and waste materials: Reconstructed mining landforms are often comprised of altered surface and subsurface profiles that vary in composition from adjacent undisturbed landscapes. LFA can be readily applied to these reconstructed surface profiles to assess the capacity of these "new landscapes" to hold resources within the system.

- Vegetation community: The EFA field procedures for vegetation assessment have been readily applied to chenopod shrublands, spinifex grasslands, eucalypt woodlands, tropical rainforests, savannah woodlands and coastal heathlands.

- Rehabilitation technique: EFA can be applied to reconstructed mining landforms which differ in slope length, gradients and outer surface profile depending on the rehabilitation techniques employed.

\subsection{The applications and uptake of LFA and EFA abroad}

EFA has been successfully tested and implemented as a tool to determine ecosystem function across a diverse range of natural and mined landscapes outside Australia including Africa, the Middle East, southern Europe and Asia (Tongway and Hindley, 2003; Maestro and Cortina, 2004; PIRSA, 2006).

Some of the recent applications of LFA and EFA abroad include the following:

- LFA is currently being used by National Parks managers and rangeland managers in South Africa, Botswana, Kenya and Ethiopia to assess overgrazing in game parks and conservation reserves (D. Tongway, pers. comm. 2008). 
- EFA mining workshops have been conducted in the South African Witwatersrand gold fields, platinum corridor, and for mines in Namibia to educate land managers in its application on rehabilitated mining landscapes.

- Two PhD studies focusing on utilizing LFA in assessing rangeland ecology in Iran are currently in progress.

- Two PhD studies focusing on utilizing EFA in assessing rangeland ecology, and mine land condition, in South Africa are currently in progress.

- The University of Alicante (Spain) have successfully implemented research projects in Spain and Libya using LFA concepts in desertification studies.

- LFA concepts were extensively used in the United Nations Compensation Commission (UNCC) evaluation of military damage caused to desert ecosystems by the 1990 Gulf War.

- The LFA Procedures Manual for Monitoring and Assessment of Landscapes (Tongway and Hindley, 2004) has recently been translated into Mandarin and Indonesian (by Dr Dwi Setyawon) and Farsi (Dr Ali Heshmati) for use in general land management.

- Fernando and Puche (2008 in draft) concluded that "this methodology (LFA) has an enormous potential to assist land managers and policy makers in the establishment of cost-effective desertification monitoring and restoration programmes in semi-arid environments".

\section{$7 \quad$ EFA in determining the thresholds for rehabilitation and closure}

A study conducted in the wet tropics of the Kelian Mine in Kalimantan Malaysia (Setyawan, 2005), clearly demonstrated that by Year 7 post rehabilitation, the principle LFA values were $70 \%$ that of the analogue, as demonstrated in Figure 4.

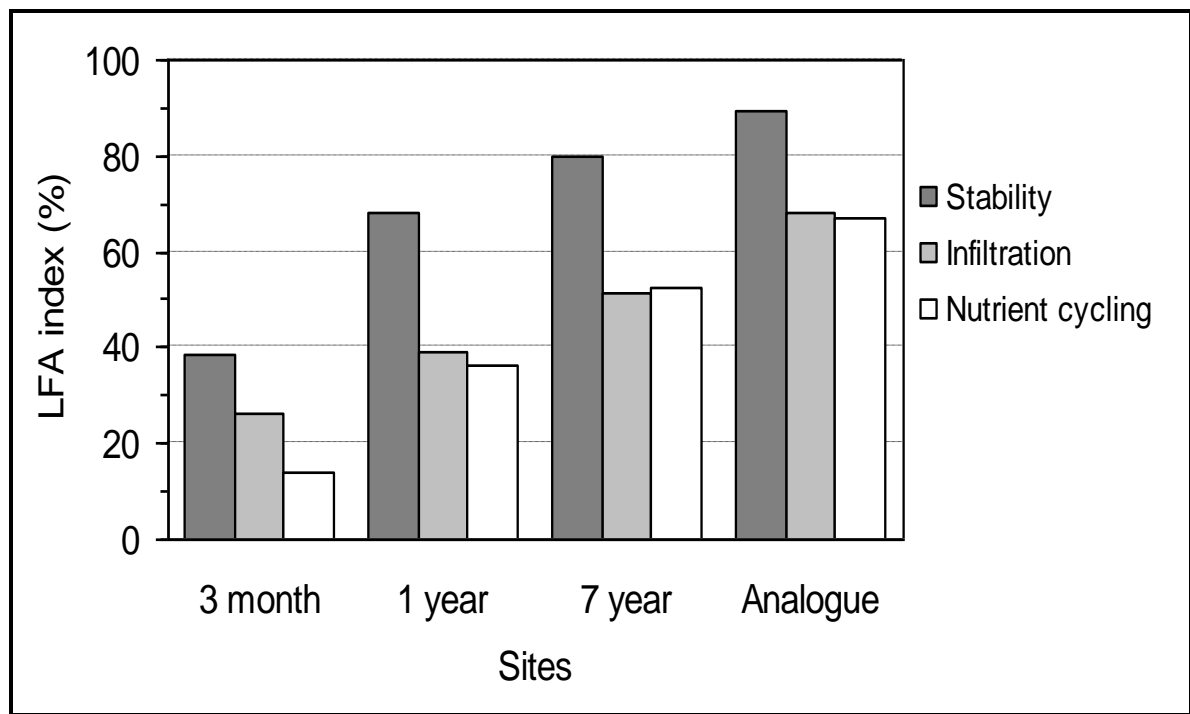

\section{Figure 4 LFA data Kelian mine rehabilitation}

The South Australian mining industry regulator PIRSA (Randall, 2004) applied a programme of research evaluation of LFA at the Cook Plains Gypsum Mine. The study concluded by suggesting that the EFA technique gives the mining industry the opportunity to achieve best-practice rehabilitation assessment and monitoring in conjunction with regulatory bodies. EFA will be useful as a quantitative tool for companies to demonstrate achievement of rehabilitation outcomes, and to support the current rehabilitation sign-off or bond review processes by government. Its use can provide a scientifically-valid method of quantifying rehabilitation success at mine sites, and a level of rehabilitation liability for bond review. There are many other scientific programmes currently being tested to monitor rehabilitated areas on mine sites, however, these are still in the experimental stage (Randall, 2004). 


\section{Use of EFA in continual improvement in rehabilitation practices}

- EFA was used to assess a series of rehabilitation trials and covers materials on dispersive and saline clays used to build the walls at the Kanowna Belle tailings facility (Outback Ecology, 2004).

- EFA was employed to monitor the progress of reinvigoration treatment to promote rehabilitation on historic landforms at each trial site at the Lawlers Gold Mine (Outback Ecology, 2005b).

- EFA was employed to determine the most effective rehabilitation strategy for drill footprints comparing ripping, versus non-ripped techniques on the Mitchell Grass Plains and arid gibber plains at Beverley Uranium mine (Outback Ecology, 2007a).

- EFA was employed to monitor the Germania Offset Block (Victoria Clearing Legislation Requirement) for Bendigo Gold. Transects were established in areas representative of the diverse heathy woodland vegetative communities and sites disturbed by fire, areas which have been physically disturbed, and undisturbed heathy woodlands. Suitable reference sites were established within the nearby Deep Lead Nature Conservation Reserve to capture any alterations in EFA data resulting from seasonal and environmental fluctuations in future assessments, and to compare progression and responses to rehabilitation management effects (Outback Ecology, 2005c).

- EFA was used to assess the effectiveness of rehabilitation trials of a series of large scale earthworks techniques at BHP Iron Ore, Yarrie Mine. Moonscaping, benching and ripping were tested and EFA was used to determine which was the most effective treatment for ecosystem success (Outback Ecology, 2007b).

Centennial Coal (2007) reports that a detailed set of completion criteria is being developed in order to provide an assessment framework for the success of the ecological and rehabilitation management measures. These criteria will relate to the objectives of the retention of existing vegetation, revegetation and regeneration activities, fauna, habitat, habitat augmentation and LFA.

Lacy and Potts (2008) report that Newmont Australia has included the aspects of LFA and EFA as a component in drafting completion criteria for many of their Australian operations (Tanami, Jundee, Granites and Woodcutters), i.e. "Demonstrate that measured values for Landform Function Analysis, and Habitat Complexity trends towards relevant reference sites, or is appropriate in terms of an appropriate regional completion criteria". This is measured by annual EFA monitoring with results provided in the annual monitoring report.

\section{EFA as a tool for reducing financial liability and giving evidence of achieving closure}

There are real and verifiable examples where EFA has been utilized to close out rehabilitation liabilities and recover monetary assurances. Staged reductions in financial sureties have been successfully negotiated at a number of sites in Western Australia, in recognition of demonstrated rehabilitation success:

- The authors are aware of a cumulative total of $\sim \mathrm{A} \$ 5.2$ million to date in the reduction of securities through the use of EFA monitoring programmes.

- The Australian division of Homestake Mining commenced a mine closure programme in 2001 that involved the recovery of performance bonds and A \$ 3 million was sought and achieved in postclosure works by demonstrating the stability of landforms and developing ecosystems through the use of EFA across four mine sites, and 43 landforms.

- At Minjar Mine 2003/04, bonds have been reduced twice, first after primary earthworks, by $\mathrm{A} \$ 116,000$ and then post year two of EFA monitoring by $\mathrm{A} \$ 250,000$.

- Resolute Mining in 2003/04, recovered A $\$ 249,000$ at Chalice Mine, A $\$ 241,000$ at Higginsville Mine, A \$559,000 at Bullabulling Mine, and A \$72,000 at Widgiemooltha Mine.

- View Resources recovered at Mt McClure Mine A\$650,000 in 2006. 
Details of the bond reductions quoted above are available to subscribers on the DoIR WA Mineral Titles on Line Service (http://www.doir.wa.gov.au/3968.aspx).

EFA has been utilized to close out rehabilitation liabilities, to recover monetary assurances, and to effect sign-off and closure at mine sites. For instance, at the Bottle Creek Mine (Anderson et al., 2002; DoIR, 2006) the Minister for State Development in Western Australia deleted all tenement conditions associated with the Bottle Creek Project and returned the bonds, thereby confirming that Norgold Limited had rehabilitated the site to the satisfaction of the State Mining Engineer. One of the monitoring tools to demonstrate that the site could be relinquished was validation of the rehabilitation and developing ecosystem using ecosystem function analysis (EFA), that reported on the site condition by the comparison of functionality displayed by the rehabilitation in comparison with analogue sites in the surrounding region (DITR, 2006). The use of a robust monitoring technique over time was able to demonstrate adequately completion criteria in the rehabilitation. This evidence was accepted by the regulator leading to the final relinquishment of the mine.

At Timbarra Mine, New South Wales, the mine closure plan includes a programme for rehabilitation performance monitoring throughout the closure period. Rehabilitation performance monitoring is based on CSIRO's ecosystem function analysis (EFA) method. CSIRO have been retained in an ongoing review capacity to validate methodologies and data interpretation (Curry, 2005).

\section{Discussion}

\subsection{Going forward}

As with all monitoring techniques, competency in the use of LFA and EFA in the field and the interpretation of data requires effective training through quality assured programmes. Teaching the technique by inclusion in universities curricula, and hands-on training for practitioners in the field, is a necessity to ensure the technique is applied competently, providing ongoing confidence in the data produced. The development of an accreditation programme would provide employers with confidence in their staff and contractors to undertake EFA and such a programme could well be expanded to include all monitoring techniques over time. Mentoring is also a valuable tool in supporting field practitioners in developing their skills with application of all monitoring tools.

EFA - the "leatherman" of monitoring tools - could be considered as an important collection of techniques in one system. It should be reinforced that EFA is not the only monitoring tool but can be a powerful component of an integrated system. The value of EFA is the ability to demonstrate, at a simple level, if an ecosystem is functional or non-functional and other tools can then be applied to focus on cause and effect. A challenge for the future is to define better and explain to practitioners how to select the most appropriate monitoring tool for their situation and stage of development.

\subsection{Summary}

Land managers require an integrated set, or toolbox, of monitoring techniques to provide them with the information they need to manage their land effectively. Many of these monitoring techniques focus on specific aspects of the environment they are measuring and do not provide the manager with a more holistic view of how the ecosystem under their control is developing or performing. Experience of using LFA and EFA over many years in a wide range of different environments has demonstrated that they are effective tools in providing this information. The choice of which technique is used, LFA or EFA, will depend on the situation and capacity and experience of the management team, and can be supported with more quantitative monitoring tools if required. It is also clear that these tools provide the regulator and other stakeholders with the sort of information they need to verify an adequate level of management performance.

The LFA and EFA monitoring techniques have been developed and scientifically validated by scientists from CSIRO's Sustainable Ecosystems over a long period. The techniques have been tested over a wide range of landforms and rehabilitation in many different ecosystems, both in Australia and overseas. The techniques bring together data from soil, nutrient cycling, vegetation structure and habitat complexity to provide a simple but powerful measure of overarching performance over time. The techniques are based on indices and data collection processes that are relatively simple and can be taught quickly by experienced operators. When applied over time, these tools provide all parties with an accurate view of how the land they are 
managing is performing. It also enables targeted treatment of areas that are not performing by indicating which aspect is not functioning in the system.

The mining industry worldwide has been quick to recognize the usefulness of this technique in the management of rehabilitated and remediated lands under their control. This has been supported by the regulatory authority in Western Australia and other Australian states, and has enabled the effective reporting of rehabilitation performance and in many cases has been the source of information to enable the reduction of securities on operations where rehabilitation has been successful. Work is currently underway to develop the relationships between EFA data and data collected from remote sensing, in particular aerial hyperspectral data. The focus of this work is to develop a set of techniques that could provide a body of landscape data sets.

\section{Conclusion}

In conclusion LFA and EFA are effective, tried-and-tested monitoring tools for measuring ecosystem performance, and the authors believe they have a important role in any integrated monitoring programme applied to demonstrate performance of rehabilitation that is a natural outcome of the mine closure process.

\section{References}

Anderson, K., Lacy, H., Jeanes, B. and Bouwhuis, E. (2002) Ecosystem Function Analysis monitoring of the decommissioned Bottle Creek Minesite Period (1998-2001), Proceedings Goldfields Environmental Management Group Workshop Kalgoorlie, Western Australia.

Centennial Coal (2007) Anvil Hill Project Referral Form. Environment Protection and Biodiversity Conservation Act 1999, Centennial Hunter Pty Limited, Muswellbrook, NSW.

Curry, N. (2005) Information Memorandum. General Manager Sustainability. Timbarra Mine, Placer Dome, Brisbane QLD.

Department of Primary Industries and Resources of South Australia (PIRSA) (2006) Ecosystem Function Analysis — a tool for monitoring mine-site rehabilitation success, http://www.pir.sa.gov.au/byteserve/minerals/references/mesa_journal/mj_35/mj35_ecosystem.pdf.

Department of Industry Tourism and Resources (DITR) (2006) Bottle Creek Case Study. Mine Closure and Completion, Leading Practice Sustainable Development Program for the Mining Industry. Commonwealth of Australia, 2006.

Environmental Protection Authority (EPA) (2006) Guidance for the Assessment of Environmental Factors. Guidance Statement 6: Rehabilitation of Terrestrial Ecosystems, June 2006, http://www.epa.wa.gov.au/docs/2184_GS6.pdf.

Krebs, C.J. (1985) Ecology: the Experimental Analysis of Distribution and Abundance. (Third Edition), Harper and Sons, London, pp. 383-385.

Lacy, H. and Potts, R. (2008) Commitment, Experience and Teamwork: The Key to a Successful Mine Closure Works Program at Tanami Mine Site. Third International Seminar on Mine Closure. I.M. Weiersbye, A.B. Fourie and M. Tibbett (eds), Australia, Perth.

Ludwig, J., Tongway, D., Freudenberger, D., Noble, J. and Hodgkinson, K. (eds) (1997) Landscape Ecology Function and Management. Principals from Australia's Rangelands, CSIRO Sustainable Ecosystems GPO.

Mackenzie, S., Jasper, D.A., Bow, B. and Lacy, H.W.B. (2007) Progressive Reduction of Liabilities and Recovery of Financial Sureties in Recognition of Successful Rehabilitation in Western Australia. Second International Seminar on Mine Closure, A.B. Fourie and M. Tibbett (eds), Australia, Perth.

Maestre, F.T. and Puche, M.D. (2008) Manuscript: JNL Applied Soil Ecology. Indices based on soil surface indicators predict ecosystem functioning in Mediterranean semiarid steppes, Área de Biodiversidad y Conservación, Departamento de Biología y Geología, Escuela Superior de Ciencias Experimentales y Tecnología, Universidad Rey Juan Carlos, 28933. Móstoles, Spain.

Maestre, F.T. and Cortina, J. (2004) Insights into Ecosystem Composition and Function in a Sequence of Degraded Semiarid Steppes Restoration Ecology, December 2004, 12 (4).

McNamara, R., Pocknee, C. and Garrahy, M. (1999) Development and implementation of a site specific overburden rehabilitation program - Bowen Basin, Central Queensland. Proceedings of 3rd Australian Workshop on Native Seed Biology for Revegetation, Perth, ACMER, Brisbane, Australia, 17 pp.

Outback Ecology (2005a) Completion Criteria Using Ecosystem Function Analysis. Internal Report. Argyle Diamonds. Kunanurra, Western Australia.

Outback Ecology (2005b) Internal Report to Barrick Lawlers Gold Mine Re-invigoration Trials on three Landforms at the Lawlers Gold Mine. Barrick Gold Corp. Australia, Perth. 
Outback Ecology (2004) Internal Report to Placer Dome Asia Pacific Kanowna Belle Gold Mine Tailings Facility Embankment Trials. Placer Dome Asia Pacific (Barrick Gold Corp), Kanowna Belle Mine, Kalgoorlie, Australia.

Outback Ecology (2007a) Internal Report to Heathgate Resources, Beverley Uranium Mine. Ecosystem Function Analysis December 2007, Heathgate Resources, 45 Grenfell Street Level 9, Adelaide S.A. 5000.

Outback Ecology (2005c) Internal Report to Bendigo Mining. Ecosystem Function Analysis of the Germania Offset Block 2005, Bendigo Gold - Bendigo Victoria. Australia.

Outback Ecology (2007b) Internal Report to BHPIO. Rehabilitation Trials at Yarrie Mine - Assessment Report EFA. BHPIO Perth, Australia.

Randall, J. (2004) Ecosystem Function Analysis - a tool for monitoring mine-site rehabilitation success. MESA Journal 35, October 24, pp. 24-27, Mining Regulation and Rehabilitation Branch, PIRSA.

Setyawan, D. (2005) Soil development, plant colonization and landscape function analysis for disturbed lands under natural and assisted rehabilitation. PhD Thesis, The University of Western Australia.

Tongway, D. and Ludwig, J. (2006) Assessment of Landscape Function as an Information Source for Mine Closure. Proceedings of the First International Seminar on Mine Closure, Andy Fourie and Mark Tibbett (eds) Australia, Perth, pp. 21-29.

Tongway, D. and Hindley, N. (2003) Indicators of Ecosystem Rehabilitation Success. Stage Two - Verification of EFA Indicators. Final report for the Australian Centre for Mining Environmental Research (ACMER).

Tongway, D. and Hindley, N. (2004) Land Function Analysis; Procedures Manual for Monitoring and Assessment of Landscapes, CSIRO, Canberra.

Tongway, D., Hindley, N., Ludwig, J., Kearns, A. and Barnett, G. (1997) Early indicators of ecosystem rehabilitation on selected minesites, Proceedings 22nd Annual Mineral Council of Australia Environmental Workshop, Canberra, ACT, pp. 494-505.

Ward, M., Jasper D. and Payne, C. (2006) Monitoring for Rehabilitation Completion and Mine Closure. Proceedings First International Seminar on Mine Closure. A.B. Fourie and M. Tibbett (eds), Australia, Perth. 
